\title{
Magnetic Resonance Imaging of Asians with Multiple Sclerosis was Similar to that of the West
}

\author{
H.T. Chong, N. Ramli, K.H. Lee, B.J. Kim, M. Ursekar, K. Dayananda, \\ B.S. Singhal, J. Chong, L.L. Chan, Y.Y. Seetoh, O. Chawalparit, \\ N. Prayoonwiwat, F.C. Chang, C.P. Tsai, K.W. Tang, P.C.K. Li, C.T. Tan
}

JOURNAL EXCHANGE. Published with permission from Neurology Asia 2004; 9: 47-53

\begin{abstract}
Magnetic resonance imaging (MRI) of the brain is the most important paraclinical diagnostic test in multiple sclerosis (MS). The appearance of MRI in Asians with MS is not well defined. We retrospectively surveyed the first brain and spinal cord MRI in patients diagnosed to have MS, according to Poser's criteria in seven regions throughout Asia to define the MRI changes among Asians with MS. There were 101 patients with first brain, and 86 with first spinal cord MRI, 66 of whom had both. The brain MRI showed a mean of 17 lesions per patient in T2 weighted images, mostly asymptomatic. Almost all the lesions were in the white matter, particularly in the juxtacortical, deep and periventricular white matter. A third of the lesions were greater than $5 \mathrm{~mm}, 14 \%$ enhanced with gadolinium. There were more supratentorial than infratentorial lesions at a ratio of 7.5: 1 . Ninety five percent of the spinal cord lesions were in cervical and thoracic regions, $34 \%$ enhanced with gadolinium. The lesions extended over a mean of $3.6 \pm 3.3$ vertebral bodies in length. Fifty $(50 \%)$ of the brain and $54(63 \%)$ of the spinal MRI patients had the optic-spinal form of MS. The MRI of the optic-spinal and classical groups of patients were similar in appearance and distribution, except that the optic-spinal MS patients have fewer brain but longer and more severe spinal cord lesions. In conclusion, the brain and spinal cord MRI of Asian patients with MS was similar to that of the West, although, in this study, Asian MS patients had larger spinal cord lesions.
\end{abstract}

RÉSUMÉ: L'imagerie par résonance magnétique est similaire chez des patients atteints de sclérose en plaques, qu'ils soient d'Asie ou de l'Ouest. L'imagerie par résonance magnétique (IRM) du cerveau est l'épreuve diagnostique paraclinique la plus importante dans la sclérose en plaques (SEP). Les caractéristiques de l'IRM chez les Asiatiques atteints de SEP sont mal connues. Nous avons analysé rétrospectivement l'IRM initiale du cerveau et de la moelle épinière chez des patients dont le diagnostic de SEP avait été fait selon les critères de Poser dans sept régions d'Asie, afin de préciser les changements observés à l'IRM chez des Asiatiques atteints de SEP. L'imagerie du cerveau était disponible chez 101 patients, celle de la moelle épinière chez 86 patients et celle du cerveau et de la moelle épinière chez 66 patients. À l'IRM du cerveau, le nombre moyen de lésions par patient était de 17 sur les images pondérées en T2, ces lésions étant en grande partie asymptomatiques. Presque toutes les lésions étaient situées dans la substance blanche, surtout juxtacorticale, profonde et périventriculaire. Le tiers des lésions étaient de plus de $5 \mathrm{~mm}$ et $14 \%$ étaient rehaussantes à l'examen avec gadolinium. Il y avait plus de lésions sus-tentorielles que sous-tentorielles, pour un ratio de 7,5 à 1. Quatre-vingt-quinze pour cent des lésions de la moelle épinière étaient dans la région cervicale et la région thoracique et $34 \%$ étaient rehaussantes à l'examen avec gadolinium. Les lésions s'étendaient en moyenne sur une longueur correspondant à 3,6 3,3 corps vertébraux. Cinquante patients (50\%) ayant subi une IRM du cerveau et 54 patients (64\%) ayant subi une IRM de la moelle épinière avaient une forme optique et spinale de la SEP. À l'IRM, l'apparence et la distribution des lésions des groupes optique-spinal et classique étaient semblables sauf que les patients atteints de la forme optique-spinale avaient moins de lésions cérébrales et des lésions plus longues et plus sévères à la moelle épinière. L'IRM du cerveau et de la moelle épinière des patients Asiatiques atteints de SEP étaient semblables à celles des patients de l'Ouest sauf qu'ils avaient de plus grosses lésions à la moelle épinière.

Can. J. Neurol. Sci. 2006; 33: 95-100

Paraclinical evidence, consisting of evoked potentials study, cerebrospinal fluid analysis or imaging techniques, has been accepted in the diagnosis of multiple sclerosis (MS). ${ }^{1}$ Magnetic resonance imaging (MRI), of the brain in particular, is known to be very helpful, with a sensitivity reaching $95 \% .^{2}$ Various brain MRI lesions were considered specific to MS in patients younger than 50 year-old; among these were periventricular lesions, ${ }^{2-4}$ gadolinium enhancement, ${ }^{4-8}$ large lesions, ${ }^{3}$ ovoid and callosal or sub-callosal lesions, ${ }^{9-11}$ and the total number of lesions or lesion
From the University of Malaya (HTC, NR,CTT), Samsung Medical Center (KHL, BJK), Sungkyunkwan University School of Medicine, Seoul, Korea; Jankharia Neuroimaging Center (MU), Mumbai, Bombay Hospital Institute of Medical Sciences (KD, BSS), Bombay, India; National University of Singapore (JC), Singapore General Hospital (LLC), National Neuroscience Institute (YYS), Singapore; Siriraj Hospital (OC, NP), Bangkok, Thailand; Veterans General Hospital (FCC, CPT), Taipei, Taiwan; Queen Elizabeth Hospital (PCKL), Hong Kong; all members of Multiple Sclerosis in Asia Pacific Study Group.

Reprint requests to: H.T. Chong, Neurology Laboratory, University of Malaya Medical Centre, 59100 Kuala Lumpar, Malaysia. 
load. ${ }^{4,12,13}$ Barkhof et al ${ }^{14}$ showed that the fulfillment of three out of four MRI criteria (gadolinium-enhanced or 9 T2 lesions, $\geq 3$ periventricular lesions, juxtacortical lesions, and infratentorial lesions) improved the specificity to $78 \%$, and the positive predictive value to $75 \%$ in the diagnosis of MS. This became the basis of new diagnostic guideline for MS, where MRI plays a central role. ${ }^{15}$

Spinal cord MRI were less well studied in MS and prospective studies are currently insufficient. ${ }^{15}$ Previous studies demonstrated that spinal cord involvement was shown as high intensity lesions on T2 weighted images, well circumscribed and mainly oval, ${ }^{16}$ with a predilection for the cervical (49-62\%) and thoracic $(38-47 \%)$ regions. ${ }^{17-19}$ Lesions were variable in size: ranges from 0.5 to 6 vertebral body segments longitudinally, ${ }^{18}$ or 2-60 mm, and the median size was $10 \mathrm{~mm} .{ }^{16}$ However, $12.5 \%$ of patients had diffuse lesions with a mean size of $11.2( \pm 5.7$, maximum 19) vertebral segments. ${ }^{19}$ The longitudinal axis of the lesions extended along the long axis of the spinal cord. ${ }^{19}$ Most patients had one $(68 \%)$ or two (19-65.4\%) lesions ${ }^{16,19}$ with a mean of $1.74 \pm 1.57^{17}$ or a median of three ${ }^{19}$ lesions per-patient. Most lesions were situated either centrally (16-72\%) or posteriorly (18-41\%). ${ }^{16,17}$ Cord atrophy was seen in $0.8-40 \%,{ }^{16-}$ 19 and cord swelling in $2.8-14 \%,{ }^{16,18,19}$ depending on the method of measurement. ${ }^{16-19}$ Gadolinium enhancement was seen in $17.2 \%$ of patients. ${ }^{19}$

Although MS is considerably less common in Asia, it has long been long been noted that there were significant differences compared with Western counterparts. Besides lower prevalence, MS in Asia has higher female preponderance, rare familial occurrence, more severe and frequent optic nerve and spinal cord attacks, resulting in greater functional disability, visual impairment and higher incidence of paroxysmal tonic spasm. Cerebral and cerebellar involvement is less common, especially among patients with the optic-spinal recurrent form, and cerebrospinal fluid oligoclonal bands are less frequently positive. ${ }^{20-26}$ These differences are not limited to Asia. Studies from Brazil, ${ }^{27-28} \mathrm{Kenya}^{29}$ Martinique (French West Indies), ${ }^{30}$ black South Africans ${ }^{31}$ and Americans of African ancestry ${ }^{32}$ have shown similar findings. Magnetic resonance imaging studies in Japan also showed a difference among the patients with disseminated ("Western") versus optic-spinal ("Asian") forms of MS. The disseminated patients had more brain lesions than the optic-spinal patients, more frequent gadolinium enhanced but fewer lesions. In the spinal cord, there was lower frequency of gadolinium enhancement, swollen and atrophied spinal cord. Gadolinium enhancement of the optic tract or nerve, and syrinxlike formation in the spinal cord were seen exclusively in the optic-spinal form of MS. Optic-spinal patients also had longer spinal cord lesions, averaging $5.8 \pm 3.2$ vertebral segments long. ${ }^{33,34}$ To-date, there were few systematic studies to characterize the brain and spinal cord MRI of MS patients elsewhere in Asia. This is a multi-centre regional collaborative study in Asia, to describe the first brain and spinal cord MRI in patients with MS, and compare the MRI of the classical and optic-spinal patients.

\section{METHODS}

We conducted a retrospective survey on the first brain and/or spinal cord MRI done according to clinical indication in seven regions across Asia (Malaysia, Korea, India, Singapore, Thailand, Taiwan and Hong Kong). The patients were diagnosed to have clinically definite MS according to Poser's criteria. ${ }^{1}$ The optic-spinal form of MS was defined as patients with recurrent myelitis and/or optic neuritis clinically, without involvement of other part of the centre nervous system. The classical form of MS was seen in patients with clinically disseminated involvement beyond optic nerve and spinal cord. The MRI was done in various centres on at least a 1.5 Tesla machine, with the minimal of T1, T2 and FLAIR weighted images, but preferably with gadolinium enhancement. The spinal cord section was $3 \mathrm{~mm}$ or less. The images were read by at least two neuroradiologists/neurologists and the interpretation reached by consensus. Where there was dissenting view, the opinion of a third neuroradiologist/neurologist was accepted as final. The results were collated and analyzed centrally.

Parametric variables were analyzed with ANOVA, and nonparametric with Fisher's exact test, chi square (with Yates' correction when necessary) or Mann-Whitney statistics. All p values of less than 0.05 were accepted as significant.

\section{RESUlts}

\section{Demography}

Of the 136 patients who initially enrolled in the study, 121 patients had sufficient clinical details to be included in the analysis. There were 101 first MRI of the brain and 86 of the spinal cord; 66 of whom had both first brain and spinal cord MRI. On average, the brain MRI was done $2.9 \pm 6.2$ years, and spinal cord MRI $3.2 \pm 7.2$ years after the first symptom. The brain MRI was done $2.2 \pm 4.9$ years and the spinal cord MRI 2.7 \pm 5.6 years after the diagnosis. The mean age was $38 \pm 11$ years, with $100(87 \%)$ female. The ethnic composition consisted of Chinese (47\%), Indians (22\%), Thais (14\%), Koreans (12\%), Malays (4\%), and Taiwan aborigines (1\%). Out of these, 68 (58\%) had optic-spinal MS. There was no difference in the age

Table 1: Demography of classical and optic-spinal multiple sclerosis patients

\begin{tabular}{l|c|c|c}
\hline & $\begin{array}{c}\text { Classical } \\
(\mathbf{N = 5 3 )}\end{array}$ & $\begin{array}{c}\text { Optic-spinal } \\
(\mathbf{N = 6 8 )}\end{array}$ & p values \\
\hline Age (years) & $37 \pm 11$ & $39 \pm 12$ & NS \\
Female (\%) & 82 & 91 & NS \\
Chinese (\%) & 39 & 54 & 0.04 \\
Course (\%) Relapsing remitting & 36 & 53 & NS \\
\multicolumn{1}{c|}{ Secondary progressive } & 3 & 2 & NS \\
$\quad$ Progressive relapsing & 2 & 1 & NS \\
$\quad$ Primary progressive & 3 & 1 & NS \\
\hline
\end{tabular}

NS $=$ no significance 
Table 2: Brain MRI findings in patients with multiple sclerosis

\begin{tabular}{|c|c|c|c|c|}
\hline & $\begin{array}{c}\text { Total } \\
(\mathrm{N}=\mathbf{1 0 1})\end{array}$ & $\begin{array}{c}\text { Classical } \\
(\mathrm{N}=51)\end{array}$ & $\begin{array}{l}\text { Optic-spinal } \\
\qquad(\mathrm{N}=\mathbf{5 0})\end{array}$ & $p$ values \\
\hline Total no. of lesions/patient & $17.0 \pm 23.0$ & $25.0 \pm 27.0$ & $9.4+13.0$ & $<0.001$ \\
\hline Cerebral atrophy, no. $(\%)(\mathrm{N}=84)$ & $21(25 \%)$ & $13 / 42(31 \%)$ & $8 / 42(19 \%)$ & NS* \\
\hline \multicolumn{5}{|l|}{ Location/distribution } \\
\hline Supratentorial & $15.0 \pm 20$ & $22.0 \pm 24$ & $8.3+12.0$ & $<0.001$ \\
\hline Periventricular WM** & $3.8 \pm 5.6$ & $5.5 \pm 6.7$ & $2.2+3.5$ & 0.011 \\
\hline Deep WM & $5.0 \pm 8.0$ & $7.2 \pm 9.5$ & $2.7+5.5$ & 0.006 \\
\hline Juxtacortical WM & $5.6 \pm 9.6$ & $8.1 \pm 12$ & $3.0+6.0$ & 0.0033 \\
\hline Corpus callosum & $0.8 \pm 1.9$ & $1.2 \pm 2.5$ & $0.4+1.0$ & NS \\
\hline Infratentorial & $2.0 \pm 3.8$ & $3.0 \pm 4.8$ & $1.0+2.2$ & $<0.001$ \\
\hline Cerebellum & $0.3 \pm 0.7$ & $0.3 \pm 0.8$ & $0.3+0.6$ & NS \\
\hline Midbrain & $0.4 \pm 1.3$ & $0.5 \pm 1.5$ & $0.2+1.0$ & NS \\
\hline Pons & $0.8 \pm 2.0$ & $1.3 \pm 2.6$ & $0.3+0.7$ & 0.0059 \\
\hline Medulla & $0.3 \pm 0.6$ & $0.5 \pm 0.8$ & $0.1+0.2$ & $<0.001$ \\
\hline \multicolumn{5}{|l|}{ Appearance of lesions } \\
\hline Gadolinium enhancement & $2.4 \pm 7.4$ & $4.4 \pm 10$ & $0.4+0.9$ & 0.016 \\
\hline Large $(\geq 5 \mathrm{~mm})$ & $5.6 \pm 12$ & $8.8 \pm 15$ & $2.3+5.6$ & $<0.001$ \\
\hline Oval/ovoid & $2.2 \pm 4.4$ & $3.2 \pm 5.5$ & $1.1+2.7$ & $<0.001$ \\
\hline Confluent & $1.4 \pm 4.0$ & $2.3 \pm 5.2$ & $0.4+1.8$ & $<0.001$ \\
\hline Perpendicular & $0.2 \pm 1.2$ & $0.4 \pm 1.7$ & $0.04+0.2$ & NS \\
\hline Hypointense on $\mathrm{T} 1$ & $3.5 \pm 8.1$ & $5.3 \pm 10.3$ & $1.6+4.3$ & 0.0093 \\
\hline Black hole on $\mathrm{T} 1$ & $0.8 \pm 2.2$ & $1.0 \pm 2.5$ & $0.7+1.9$ & NS \\
\hline
\end{tabular}

$* \mathrm{NS}=$ no significance, ${ }^{*} * \mathrm{WM}=$ White matter. Unless otherwise stated, the numbers are expressed as mean $\pm \mathrm{sd}$.

and sex of the classical and optic-spinal groups. Chinese is overrepresented in the optic-spinal group (Table 1).

\section{Brain MRI}

Of the 101 patients, $12 \%$ had normal MRI brain. There were on average 17 lesions in the T2 weighted images of brain MRI, most of these were asymptomatic. There were 69 patients $(68 \%)$ who had four or more lesions on the brain MRI, 50 patients $(51 \%)$ who had nine or more lesions. There were many more lesions supratentorially than infratentorially, with an average ratio of $7.5: 1$. Almost all of these lesions were located in the white matter, with rare patients $(6 / 101$ or $6 \%)$ having gray matter lesions (Tables 2 and 3). Most of the lesions were located in the juxtacortical, periventricular and deep white matter. Corpus callosum lesions were less common. Cerebral atrophy was seen in about a quarter of the patients. Infratentorially, about half of the lesions were located in the pons. A third of the lesions were greater than $5 \mathrm{~mm}$. The large lesions were typically discrete and ovoid, some of which were confluent. Twenty-one percent of the lesions were hypointense on T1 weighted images, $14 \%$ enhanced with gadolinium. Black holes, with the same intensity as cerebrospinal fluid, were seen in $5 \%$ of lesions.

Fifty of the 101 patients $(50 \%)$ had optic-spinal MS. There were significantly more lesions among the classical MS group as
Table 3: Unusual brain MRI features

\begin{tabular}{c|c|c|l}
\hline Patient & Age, ethnicity, sex & Type of MS & \multicolumn{1}{|c}{ Brain MRI } \\
\hline 1 & 41, Korean female & Classical & $\begin{array}{l}\text { One 3-5 mm cortical } \\
\text { lesion, one 3-5 mm basal } \\
\text { ganglial lesion }\end{array}$ \\
\hline 2 & $\begin{array}{c}41, \text { Malaysian } \\
\text { Chinese female }\end{array}$ & Classical & $\begin{array}{l}\text { One 12x16 mm oedema- } \\
\text { tous cortical lesion }\end{array}$ \\
\hline 4 & 26, Korean female & Classical & $\begin{array}{l}14 \text { cortical lesions, each } \\
\geq 5 \text { mm }\end{array}$ \\
\hline 5 & 33, Korean female & Classical & $\begin{array}{l}\text { Large confluent lesion } \\
\text { extending from basal } \\
\text { ganglia to the optic chi- } \\
\text { asm, }>35 m m\end{array}$ \\
\hline 6 & 34, Korean female & Optic-spinal & $\begin{array}{l}3 \text { basal ganglia lesions, } \\
\text { largest 25 x } 8 \text { mm }\end{array}$ \\
\hline & Classical & $\begin{array}{l}\text { Large lesion extending } \\
\text { from both forceps to the } \\
\text { external capsule and the } \\
\text { lateral wall of the third } \\
\text { ventricle/hypothalamic } \\
\text { region. }\end{array}$ \\
\hline
\end{tabular}


Table 4: Spinal cord MRI features

\begin{tabular}{|c|c|c|c|c|}
\hline & $\begin{array}{c}\text { Total } \\
(\mathrm{N}=\mathbf{8 6})\end{array}$ & $\begin{array}{c}\text { Classical } \\
(\mathrm{N}=32)\end{array}$ & $\begin{array}{c}\text { Optic-spinal } \\
(\mathrm{N}=54)\end{array}$ & p values \\
\hline Total no. of lesions & 120 & 48 & 72 & \\
\hline No. of lesions/patient & $1.4 \pm 1.1$ & $1.5 \pm 1.5$ & $1.3 \pm 0.8$ & NS* \\
\hline Size (no. vertebral bodies) & $3.6 \pm 3.3$ & $2.5 \pm 2.3$ & $4.2 \pm 3.6$ & 0.001 \\
\hline No. of large lesions** & $56(47 \%)$ & $14(29 \%)$ & $42(54 \%)$ & 0.012 \\
\hline \multicolumn{5}{|l|}{ Location } \\
\hline Cervical & $61(51 \%)$ & $29(61 \%)$ & $32(44 \%)$ & NS \\
\hline Thoracic & $43(36 \%)$ & $13(27 \%)$ & $30(42 \%)$ & NS \\
\hline Cervicothoracic & $10(8 \%)$ & $4(8 \%)$ & $6(8 \%)$ & NS \\
\hline Thoracolumbar & $3(3 \%)$ & $2(4 \%)$ & $1(1 \%)$ & NS \\
\hline Lumbar or sacral & $2(2 \%)$ & 0 & $2(3 \%)$ & NS \\
\hline Entire spine & $1(1 \%)$ & 0 & $1(1 \%)$ & NS \\
\hline \multicolumn{5}{|l|}{ Cross section appearance } \\
\hline Central & 17/101 (17\%) & $6 / 41(15 \%)$ & $11 / 60(18 \%)$ & NS \\
\hline Lateral & $61 / 101(60 \%)$ & $32 / 41(78 \%)$ & $29 / 60(48 \%)$ & 0.0052 \\
\hline Complete cross section & $23 / 101(23 \%)$ & $3 / 41(7 \%)$ & $20 / 60(33 \%)$ & 0.0048 \\
\hline \multicolumn{5}{|l|}{ T1 weighted imges } \\
\hline Gadolinium enhancement & $34 / 99(34 \%)$ & $14 / 39(36 \%)$ & $20 / 60(33 \%)$ & NS \\
\hline Hypointense lesions & $30 / 104(29 \%)$ & $6 / 39(15 \%)$ & $24 / 65(37 \%)$ & 0.034 \\
\hline Black holes (syrinx-like) & $3 / 104(3 \%)$ & $0 / 39(0 \%)$ & $3 / 65(5 \%)$ & NS \\
\hline Swelling & $24 / 105(23 \%)$ & $5 / 39(13 \%)$ & $19 / 66(29 \%)$ & NS \\
\hline Atrophy & $8 / 105(8 \%)$ & $2 / 39(5 \%)$ & $6 / 66(9 \%)$ & NS \\
\hline
\end{tabular}

$* \mathrm{NS}=$ no significance, ${ }^{*}$ Large lesion $=$ lesions larger than two vertebral body segments.

compared to the optic-spinal group (Table 2). Only one classical MS patient had no lesion in the brain MRI (2\%), whereas there were 13 patients $(26 \%)$ in the optic-spinal MS group ( $\mathrm{p}=0.0013)$. There were 43 patients $(84 \%)$ who had four or more lesions on brain MRI in the classical group, as compared to 26 patients $(52 \%)$ in the optic-spinal group $(\mathrm{p}=0.001)$. Similarly, 33 patients $(65 \%)$ had nine or more lesions in the classical MS group, as compared to 17 patients $(34 \%)$ in the optic-spinal group $(\mathrm{p}=0.0039)$. The distribution and appearance of lesions were similar in classical as compared to optic-spinal groups. Patients with classical MS had significantly more lesions than opticspinal MS in all areas except for corpus callosum, cerebellum and midbrain (Table 2). Both forms of MS had similar numbers of lesions in the cerebellum (Table 2), with nine patients in each group having between one to three lesions in the cerebellum. However, due to the fewer number of lesions elsewhere, the optic-spinal patients had proportionally higher number of lesions in cerebellum $(2.8 \%, 13 / 468$ versus $1.3 \%, 16 / 1269, \mathrm{p}=0.048)$. Optic-spinal patients were more likely to have cerebellar lesions larger than 5 X $5 \mathrm{~mm}$, though this was not statistically significantly $(0.8 \pm 1.0$ versus $0.2 \pm 0.4$ large lesions, $\mathrm{p}=0.14)$.

Cerebral atrophy was related to total number of lesion or lesion load. Those with cerebral atrophy (31 \pm 29 lesions) had significantly more lesions than those who did not $(13 \pm 19$ lesions, $\mathrm{p}=0.001$ ). There was more cerebral atrophy among the classical as compared to optic-spinal MS patients. However, this was not statistically significant (Table 2). There were six patients $(6 \%)$ with unusual brain MRI features which are detailed in Table 3. These patients had gray matter lesions mainly in basal ganglia, hypothalamus and optic chiasm. They were mainly seen among the Korean patients.

\section{Spinal cord MRI}

Of the 86 patients, there were all together 120 spinal cord lesions. The lesions were ovoid, well circumscribed and hyperintense on T2 weighted images. There was on average 1.4 lesions per-patient. Ten patients $(12 \%)$ had no spinal cord lesion, $48(56 \%)$ had one, $20(23 \%)$ had two, seven $(9 \%)$ had three or more lesions. The average size of the lesions was 3.6 vertebral body segments. Fifty-nine-percent of these lesions were located in the cervical or cervico-thoracic cord, $95 \%$ of the lesions were in the cervical and thoracic spinal cord (Table 4). Three fifths of the lesions were situated at the lateral or peripheral aspect of the cord. More than a fifth involved the whole cross section of the cord. A third of the lesions were enhanced with gadolinium, more than a fifth of the lesions were associated with focal cord swelling. More than a quarter was hypointense on T1 weighted images, but only $3 \%$ had syrinx-like black holes, and $8 \%$ had atrophy (Table 4). 
Fifty four patients had optic-spinal MS. These patients had similar number, locations and appearances of lesions as the classical MS patients. However the optic-spinal patients had significantly longer and severe lesions. The later is reflected by more optic-spinal patients with cord swelling, involvement of complete cross section, hypointense lesions, atrophy, and syrinxlike black holes, though only the hypointense lesions were statistical significant (Table 4).

\section{Discussion}

Our study showed that there were many similarities in the appearance of brain and spinal cord MRI in Asian MS patients as compared to those reported from the West. ${ }^{2-14}$ The typical appearance of a brain MRI in our patient is one with many T2 hyperintense lesions, ${ }^{4,12,35} 68 \%$ had more than four lesions as suggested by Paty et $\mathrm{al}^{2}$ and $51 \%$ had more than nine lesions as in Barkhof et al. ${ }^{14}$ These lesions were almost entirely situated in the white matter, especially in the periventricular, ${ }^{2-4,14,35}$ juxtacortical and deep white matters. ${ }^{14} \mathrm{~A}$ third of the lesions were larger than $5 \mathrm{~mm} .^{3}$ They were typically discrete and ovoid. ${ }^{9-11}$ Forteen percent of the lesions enhanced with gadolinium. ${ }^{4-7,14}$ There were more supratentorial than infratentorial lesions. 3,14

There were also many similarities in the spinal cord MRI of our patients and those reported from the West. ${ }^{16-19}$ The spinal cord MRI of our patients typically showed eccentric or peripheral well circumscribed T2 hyperintense ovoid lesions, a third enhanced with gadolinium. The lesions were almost exclusively in the cervical and thoracic cord. However, the average size of the spinal cord lesions of our patients was 3.6 vertebral body segments, larger than that seen in Western patients. Long segment spinal cord lesions in MRI has been previously noted in the Asian patients with $\mathrm{MS},{ }^{20,33,34}$ though large lesions are not rare among MS patients in the West. ${ }^{17-19}$ Twenty-three-percent of our patients had cord swelling, which is higher than $2.8-14 \%$ quoted from the West. ${ }^{16,18,19}$

Comparing the optic-spinal with the classical form of MS among our patients, there were also many similarities of MRI lesions between the two groups, in its distribution and appearance. The optic-spinal patients had fewer brain lesions in all locations except the cerebellum. However, even among the optic-spinal group, 52\% had four or more lesions, and 34\% had nine or more lesions on brain MRI. In the spinal cord, the lesions in the optic-spinal group were larger and more severe. These differences have been noted in the previous studies. ${ }^{20,33,34}$

The similarity in MRI findings between our patients and MS patients in the West, and classical versus optic-spinal MS among our patients, is highly relevant to the recent renewed interest in Devic's disease (neuromyelitis optica). There is a move to redefine Devic's disease and regard it as a distinct disease entity apart from MS, and to lump Asians with optic-spinal MS with the re-formulated Devic's disease. ${ }^{36,37}$ This study on the other hand, demonstrated the many similarities between the MRI results of Asian and Western MS patients, and between opticspinal and classical MS patients among Asians. ${ }^{20}$

\section{ACKNOWLEDGEMENTS}

Our gratitude to Dr B. Ong, National University Hospital and Serono Asia Pacific for their various assistance.

\section{REFERENCES}

1. Poser CM, Paty DW, Scheinberg L, et al. New diagnostic criteria for multiple sclerosis: Guidelines for research protocols. Ann Neurol. 1983; 13(3): 227-31.

2. Paty DW, Oger JJF, Kastrukoff LF, et al. MRI in the diagnosis of MS: A prospective study with comparison of clinical evaluation, evoked potentials, oligoclonal banding, and CT. Neurology. 1988; 38: 180-5.

3. Fazekas F, Offenbacher H, Fuchs S, et al. Criteria for an increased specificity of MRI interpretation in elderly subjects with suspected multiple sclerosis. Neurology. 1988; 38: 1822-5.

4. Lycklama A, Nijeholt GJ, van Walderveen MAA, et al. Brain and spinal cord abnormalities in multiple sclerosis: Correlation between MRI parameters, clinical subtypes and symptoms. Brain. 1998; 121: 687-97.

5. Grossman RI, Gonzalez-Scarano F, Atlas SW, Galetta S, Silberberg DH. Multiple sclerosis: Gadolinium enhancement in MR imaging. Radiology. 1995; 196: 505-10.

6. Katz D, Taubenberger J, Raine C, McFarlin D, McFarland H. Gadolinium-enhancing lesions on magnetic resonance imaging: Neuropathological findings. Ann Neurol. 1990; 28: 243.

7. Nesbit GM, Forbes GS, Scheithauer BW, Okazaki H, Rodriguez M. Multiple sclerosis: Histopathologic and MR and /or CT correlation in 37 cases at biopsy and three cases at autopsy. Radiology. 1991; 180: 467-74.

8. Tas MW, Barkhof F, van Walderveen MAA, Polman CH, Hommes OR, Valk J. The effect of gadolinium on the sensitivity and specificity of MR in the initial diagnosis of multiple sclerosis. Am J Neuroradiol. 1995; 16: 259-64.

9. Gean-Marton AD, Vezina LG, Marton KI, et al Abnormal corpus callosum: A sensitive and specific indicator of multiple sclerosis. Radiology. 1991; 180: 215-21.

10. Horowitz AL, Kaplan RD, Grewe G, White RT, Salberg LM. The ovoid lesion: a new MR observation in patients with multiple sclerosis. Am J Neuroradiol. 1989; 10: 303-5.

11. Simon JH, Holtas SL, Schiffer RB, et al. Corpus callosum and subcallosal-periventricular lesions in multiple sclerosis: Detection with MR. Radiology. 1986; 160: 363-7.

12. Morrissye SP, Miller DH, Kendall BE, et al. The significance of brain magnetic resonance imaging abnormalities at presentation with clinically isolated syndromes suggestive of multiple sclerosis. Brain. 1993; 116: 135-46.

13. O'Riordan JI, Thompson AJ, Kingsley DPE, et al. The prognostic value of brain MRI in clinically isolated syndromes of the CNS. A 10-year follow-up. Brain. 1998; 121: 459-503.

14. Barkhof F, Filippi M, Miller DH, et al. Comparison of MRI criteria at first presentation to predict conversion to clinically definite multiple sclerosis. Brain. 1997; 120: 2059-69.

15. McDonald WI, Compston A, Edan G, et al. Recommended diagnostic criteria for multiple sclerosis: Guidelines from the international panel on the diagnosis of multiple sclerosis. Ann Neurol. 2001; 50: 121-7.

16. Thielen KR, Miller GM. Multiple sclerosis of the spinal cord: Magnetic resonance appearance. Neuroradiology. 1996; 20(3): 434-8.

17. Kidd D, Thorpe JW, Thompson AJ, et al. Spinal cord MRI using multi-array coils and fast spin echo. Neurology. 1993; 43: 2632-7.

18. Honig L, Sheremata W. Magnetic resonance imaging of spinal cord lesions in multiple sclerosis. J Neurol Neurosurg Psychiatry. 1989; 52: 469-6.

19. Bot JCJ, Barkhof F, Polman CH, et al. Spinal cord abnormalities in recently diagnosed MS patients: Added value of spinal MRI examination. Neurology. 2004; 62: 226-33.

20. Chong HT, Li PCK, Ong B, et al. Severe spinal cord involvement is a universal feature of Asians with multiple sclerosis: A joint Asian study. Neurol J Southeast Asia. 2002; 7: 35-40.

21. Kuroiwa Y, Igata A, Itahara K, Koshijima S, Tsubaki T. Nationwide survey of multiple sclerosis in Japan. Clinical analysis of 1084 cases. Neurology. 1975; 25: 845-51. 
22. Kuroiwa Y, Hung TP, Landsborough D, Park CS, Singhal BS. Multiple sclerosis in Asia. Neurology. 1977; 27: 188-92.

23. Tan CT. Multiple sclerosis in Malaysia. Arch Neurol. 1988; 45(6): 624-7.

24. Tan CT. Multiple sclerosis in Malaysia. Neurol J Southeast Asia. 1997; 2: 1-5.

25. Vejjajiva A. Multiple sclerosis in Thailand. Neurol J Southeast Asia. 1997; 2: 7-10.

26. Thirugnanam U. Multiple sclerosis: A retrospective review of 30 cases from Singapore. Neurol J Southeast Asia. 1997; 2: 171-5.

27. Arruda WO, Scola RH, Teive HA, Werneck LC. Multiple sclerosis: report on 200 cases from Curitiba, Southern Brazil and comparison with other Brazilian series. Arq Neuropsiquiatr. 2001; 39 (2A): 165-70.

28. Lana-Peixoto MA, Lana-Peixoto MI. Is multiple sclerosis in Brazil and Asia alike? Arq Neuropsiquiatr. 1992; 50(4): 419-25.

29. Kioy PG. Emerging picture of multiple sclerosis in Kenya. East Afr Med J. 2001; 78: 93-6.

30. Cabre P, Heinzlef O, Merle H, et al. MS and neuromyelitis optica in Martinique (French West Indies). Neurology. 2001; 56: 507-14.

31. Modi G, Mochan A, Modi M, Saffer D. Demyelinating disorder of the central nervous system occurring in black South Africans. J Neurol Neurosurg Psychiatry. 2001; 70: 500-5
32. Cree BAC, Khan O, Bourdette D, et al. Clinical characteristics of African Americans vs Caucasian Americans with multiple sclerosis. Neurology. 2004; 63: 2039-45.

33. Kira J, Kanai T, Nishimura Y, et al. Western versus Asian types of multiple sclerosis: immunogenetically and clinically distinct disorders. Ann Neurol. 1996; 40:569-74.

34. Misu T, Fujihara K, Nakashima I, et al. Pure optic-spinal form of multiple sclerosis in Japan. Brain. 2002; 125: 2460-8.

35. Lee KH, Hashimoto SA, Hooge JP, et al. Magnetic resonance imaging of the head in the diagnosis of multiple sclerosis: A prospective 2-year follow-up with comparison of clinical evaluation, evoked potentials, oligoclonal banding, and CT. Neurology. 1991; 41: 657-60.

36. Weinshenker BG. Neuromyelitis optica: what it is and what it might be. Lancet 2003; 361: 889-90.

37. Weinshenker BG, Fujihara K, Pittock SJ, et al. The Asian opticspinal form of multiple sclerosis is the same entity as neuromyelitis optica in Caucasians: insight from a novel serum marker. Neurology. 2004; 62(Suppl 5): A480-1. 